\title{
Disparity, Deprivation and Discrimination in Rural India
}

Raghav Gaiha ${ }^{1}$, Ganesh Thapa ${ }^{2}$, Katsushi Imai ${ }^{3}$ and Vani S. Kulkarni ${ }^{4}$

December 2007

Katsushi.Imai@manchester.ac.uk

1. Faculty of Management Studies, University of Delhi

2. Regional Economist, Asia and the Pacific Division, IFAD

3. School of Economic Studies, University of Manchester

4. Centre for Population and Development Studies, Harvard University

Brooks World Poverty Institute ISBN : 978-1-906518-12-7

\section{BWPI Working Paper 13}




\begin{abstract}
Despite glowing accounts of how well the Indian economy has performed in recent years, some disadvantaged groups-the Scheduled Castes (SC) and Scheduled Tribes (ST)- remain mired in acute poverty. The present study assesses their poverty and relative deprivation, and the underlying factors. Our analysis of the $61^{\text {st }}$ round of the NSS for 2004-05 confirms higher incidence and intensity of poverty among the STs and SCs, relative to non-ST/SC (Others). A decomposition of poverty gap suggests that a large part of the gap between the ST and Others is due to differences in returns or structural differences while among the SCs it is due largely to differences in characteristics or endowments. Whether these structural differences are a reflection of 'current' discrimination is far from self-evident, given the important role of personal identity in determining performance. The policy design therefore cannot be limited to enhancing the endowments of the STs, SCs and other disadvantaged groups. While some of the disparity in living standards may have elements of discrimination, subject of course to the measurement problems, it is arguable that lower quality of education, location in remote, inaccessible areas with limited infrastructure and market access cause poverty and inequity to persist.
\end{abstract}

Keywords: poverty, disparity, endowments, returns, identity, discrimination.

Raghav Gaiha, Faculty of Management Studies, University of Delhi

Ganesh Thapa, Regional Economist, Asia and the Pacific Division, IFAD

Katsushi Imai, School of Economic Studies, University of Manchester

Vani S. Kulkarni, ' Centre for Population and Development Studies, Harvard University 


\section{Disparity, Deprivation and Discrimination in Rural India ${ }^{1}$}

\section{Introduction}

Despite glowing accounts of how well the Indian economy has performed in recent years, some disadvantaged groups-the Scheduled Castes (SC) and Scheduled Tribes (ST)- remain mired in acute poverty ${ }^{2}$. A recent study (Kijima, Y. (2006) "Caste and Tribe Inequality: Evidence from India, 1983-1999", Economic Development and Cultural Change, vol. 54) offers some surprising evidence on relative disparity in living standards (or, more precisely, in expenditure per capita) between these disadvantaged groups and Others in rural India, long after the Government of India introduced its policy of affirmative action (e.g. quotas in state legislatures). This disparity reflects not just lower endowments of human and physical capital (e.g. education and land owned, respectively) but also lower returns on them among the SC and ST households. While there has been some reduction in the expenditure disparity over the period 1983-99, its decomposition into two components viz. (i) lower endowments, and (ii) lower returns, is worrying.

The SC were less worse-off than the ST in both 1983 and 1999. However, the sources of their disparities differ. While the SC households were more deprived (relative to the non-SC/ST households or Others) due equally to lower endowments and lower returns, the ST's deprivation resulted largely from lower endowments (about two-thirds). What is indeed surprising is that the relative importance of these sources has remained unchanged over the period 1983-99.

The present study throws new light on the sources of persistent poverty and inequity in rural India, drawing upon the $61^{\text {st }}$ round of the NSS covering the period 2004-05. While the focus is on the ST and SC, as in Kijima (2006), Gang et al. (2007), Borooah (2005), and Borooah et al. (2007), we explore some new dimensions linking identity and performance and their implications for policy design. Specifically, it is argued that while discrimination against the ST and SC cannot be ruled out, there is a risk of exaggerating its role in explaining the deprivation of these groups relative to others.

\section{Review of literature}

There has been a spate of studies in recent years, designed to assess the sources of inequality and poverty among different ethnic/caste groups. Two studies (Gang et al.

\footnotetext{
${ }^{1}$ This is based on a larger study entitled "Endowments, Discrimination and Deprivation among Ethnic Groups in Rural India". We are grateful to T. Elhaut, Director, Asia and the Pacific Division, IFAD, for his support and advice. This draft has benefited from discussions with P. L. Scandizzo, Anil Deolalikar, C. Palmeri, M. Donnat, M. Pryor Galletti, Atsuko Toda, Raghbendra Jha, Shylashri Shankar, Bina Agarwal and Alain de Janvry. The computations were carried out by Raj Bhatia with admirable competence and efficiency. S. Vaid and Valentina Camaleonte provided valuable research support.

2 The 1950 Constitution established state-specific lists which identified the castes and tribes that fall in the categories of Scheduled Castes (SCs) and Scheduled Tribes (STs), respectively. The criteria used are shown in the Annex.
} 
2006, and Kijima, 2006) are of particular interest. As the models and decomposition procedures used are reviewed elsewhere (Gaiha et al. 2007), the main findings are summarised below.

Since Gang et al (2006) use a sophisticated methodology, and the $50^{\text {th }}$ round of the NSS for 1993-94, we review their findings first. The centrepiece of their analysis is a decomposition of poverty incidence gap (or the head-count index of poverty) between the ST, SC and Others into two components. One is the characteristic component that measures the contribution of differences in characteristics or endowments (e.g. years of schooling). The second is referred to as the structural component as it takes into account the contribution of differences in the returns to assets and other household characteristics - including location.

- SC and ST households accounted for 16.5 per cent and 8.1 per cent, respectively, of India's population, but accounted for 43.3 per cent of the rural poor in 1993-94.

- The proportions of poor SC and ST households were 49.2 and 50.3 per cent, respectively, as compared with a proportion of 33.1 per cent among rural non-scheduled households (hereafter referred to as Others). So the poverty incidence gaps were 16.1 per cent between SC and Others, and 17.2 per cent between ST and Others.

- The 'predicted' poverty incidence gaps turn out to be 14.9 per cent for the SCs, and 16.2 per cent for the STs ${ }^{3}$.

- A large fraction of the difference in poverty incidence between SC and non-scheduled households (62.5 per cent) is due to differences in levels of characteristics (e.g. education, occupation) while 37.5 per cent is due to differences in returns to these characteristics/endowments.

- The characteristic effect of occupation contributes about 35.1 percent to the poverty incidence gap (e.g. less remunerative occupations such as agricultural labour as opposed to self-employment in agriculture).The structural effect (or the difference in returns) is, however, smaller (barely 19 per cent), implying that even if the occupation were the same, SC households are rewarded less than Others. In other words, for example, the agricultural wage rate for SC household members will be lower. The characteristic effect of land owned contributes 8-12 per cent of the poverty incidence gap but there is no difference in returns.

- $\quad$ Between the ST and Others, 39 per cent of the poverty gap is due to the characteristic effect. Difference in educational attainment, for example, accounts for 23.5 per cent of the poverty incidence gap between these two groups. The occupational distribution explains 18 per cent of the higher poverty among ST households. By contrast, 61 per cent of the gap between ST and Others is due to structural differences. The difference in returns to education is negligible but that in returns to occupation is substantial (about 29 per cent).

\footnotetext{
${ }^{3}$ The predicted poverty estimates are obtained from an expenditure function, estimated using household data. For details, see Gang et al. (2006).
} 
In a comprehensive and definitive recent contribution, Kijima (2006) offers a comparative analysis of disparity in living standards among ST, SC and non-ST/SC households (Others) in rural India over the period 1983-1999, based on various rounds of the National Sample Survey (NSS) ${ }^{4}$. He also uses a decomposition procedure which in part overcomes the ambiguity in measuring the contributions of attributes and structure to disparity in living standards of SC, ST, and Others. ${ }^{5}$

\section{Table 1}

Decomposition of Sources of Inequality in (Log) Per Capita Expenditure

\begin{tabular}{|c|c|c|c|}
\hline Social Group/Year & $\begin{array}{c}\text { Difference in } \\
\text { expenditure }\end{array}$ & $\begin{array}{c}\text { Difference Due to } \\
\text { Characteristics (\%) }\end{array}$ & $\begin{array}{c}\text { Difference Due } \\
\text { to Structure } \\
\text { (\%) }\end{array}$ \\
\hline $\mathbf{S T}$ & & & \\
\hline $\mathbf{1 9 8 3}$ & .315 & 64.3 & 35.7 \\
\hline $\mathbf{1 9 8 7}$ & .297 & 58.3 & 41.7 \\
\hline $\mathbf{1 9 9 3}$ & .254 & 66.6 & 33.4 \\
\hline $\mathbf{1 9 9 9}$ & .267 & 66.6 & 33.4 \\
\hline $\mathbf{S C}$ & & & 54.8 \\
\hline $\mathbf{1 9 8 3}$ & .228 & 45.2 & 50.1 \\
\hline $\mathbf{1 9 8 7}$ & .216 & 49.9 & 49.1 \\
\hline $\mathbf{1 9 9 3}$ & .224 & 50.9 & 49.8 \\
\hline $\mathbf{1 9 9 9}$ & .191 & 50.2 & \\
\hline
\end{tabular}

Source: Kijima (2006)

Some of the findings reinforce the basic motivation for the present study as well as adding some new dimensions to anti-poverty strategy. The main findings are summarised below.

- Two thirds of the disparities between ST and non ST/SC households are due to differences in characteristics but 50 per cent or less among SC households.

- The structural component declined slightly among both ST and SC households.

- To shed more light on the underlying reasons, the explanatory variables are divided into demographic characteristics, education, land, and location. The results show that (a) the characteristic disparities between the ST and non-SC/ST are mainly due to education and location differences. In the case of SC, however, differences in land ownership contribute one fourth of the characteristic difference. (b) The structural difference between the ST and the non-SC/ST are due mainly to differences in the returns to location dummies. By contrast, in the case of the SC, the differences in the returns to education contribute a large part of the structural differences, especially in the 1990s.

\footnotetext{
4 The indicator used is expenditure per capita.

${ }^{5} \mathrm{An}$ issue in the decomposition is that the results vary with the reference group (in Gang et al. (2006), for example, the reference group is Others). Kijima (2006) seeks to overcome this difficulty by considering a composite group. For a critique, see Gaiha et al. (2007).
} 
Some light is also thrown on why the structural differences are so large for ST and SC households. Let us first consider the case of the ST.

- Districts with higher proportions of the ST are associated with poorer public goods such as schools, tapped water, paved roads, electricity, and health facilities. However, even when the effect of location is controlled for, structural differences still account for about one-third of the disparities. (b) Another possibility examined is whether returns to land and education also change with agro-ecological conditions. While returns to land vary with district level indicators of development, the returns to education do not.

- In an interesting decomposition for the SC, an attempt is made to examine whether occupational segregation has a role in explaining the structural difference between them and non-SC/ST households ${ }^{6}$. The component of occupational structure accounts for 54 per cent of the total structural difference between the SC and non-SC/ST households in 1983. This declined to 37 per cent in 1999. However, the difference in the characteristics and the difference in the returns within occupation increased in the 1980s and 1990s. But it is unclear how much of the structural difference is due to "current discrimination" against the SC. Historical patterns of employment may influence the SC's choice of occupations through low expectations and aspirations that force them to accept lower status jobs ${ }^{7}$. If job searches among low-caste men largely depend on caste-based contacts and networks, occupational distributions are likely to persist over time ${ }^{8,9}$.

In sum, the evidence reviewed confirms that greater deprivation among the ST and SC is due to both lower endowments and lower returns to them. However, their relative importance varies, depending on what the welfare indicator is. If, for example, the focus is on poverty gap, among the ST, lower returns have a larger role than lower endowments in explaining their relative deprivation while among the $\mathrm{SC}$, the latter matter more.

\section{Analysis with the $61^{\text {st }}$ Round of the NSS}

\section{(a) Endowments}

Let us first construct a profile of three social groups viz. the SC, ST and nonSC/ST/Others in terms of their endowments (i.e. human and physical capital) and occupational distribution, based on the $61^{\text {st }}$ round of the NSS for 2004-05.

\footnotetext{
${ }^{6}$ For details of the decomposition, see Kijima (2006).

${ }^{7}$ See Akerloff and Kranton (2000), Hoff and Pandey (2005) and Hoff et al. (2005).

${ }^{8}$ For an analysis of persistent disadvantages that SC/ST households face in Uttar Pradesh, see Kozel and Parker (2003). Their finding that "while about half the difference in welfare between the two groups (i.e. the SC/ST and the majority) could be attributed to differences in asset holdings, a roughly equal share was due to differences in returns to asset stocks". Since various studies have drawn attention to not only differences in household attributes between SC and ST households but also in structural effects, the lumping together of SC/ST limits the usefulness of this study.

${ }^{9}$ The results are not dissimilar with the Neumark (1988) decomposition in which the reference group is a composite of the three groups in question. For details, see Kijima (2006).
} 
Among the ST, about one-third were landless while the majority (about 59 per cent) operated some land (0.1-2.5 ha). A small fraction (a little over 7 per cent) operated $>2.5$ ha. This distribution contrasts with that for the SC, as the majority (about 62 per cent) were landless, and a little over one-third operated small areas (0.1-2.5 ha). Barely 2 per cent operated $>2.5$ ha. The distribution of Others was similar to that of the ST.

\section{Table 2}

Cross-Classification of SC, ST, and Others by Land Operated ${ }^{1}$

\begin{tabular}{|c|c|c|c|c|}
\hline $\begin{array}{c}\text { Social } \\
\text { Group/Land } \\
\text { Operated }\end{array}$ & $\mathbf{0 - 0 . 1 ~ h a ~}$ & $\mathbf{0 . 1 - 2 . 5}$ ha & >2.5 ha & Total \\
\hline ST & 34.03 & 58.59 & 7.38 & 100 \\
\hline SC & $(8.57)$ & $(12.87)$ & $(11.56)$ & $(10.91)$ \\
\hline Others & $(30.62$ & 36.00 & 1.98 & 100 \\
& 38.96 & $(15.52)$ & $(6.08)$ & $(21.42)$ \\
\hline Total & $(60.80)$ & $(71.60)$ & 8.48 & 100 \\
& 43.36 & 49.67 & $(82.36)$ & $(67.67)$ \\
\hline & $(100)$ & $(100)$ & 6.97 & 100 \\
\end{tabular}

1. Land owned and possessed.

All groups had limited access to irrigation, with large majorities enjoying little or no access (about 81 per cent of the ST, about 77 per cent of the SC and about 63 per cent of Others). While one-third of Others had small irrigated areas (0.1-2.5 ha), much smaller proportions of the ST and SC did.

Table 3

Cross-Classification of SC, ST, and Others by Land Irrigated ${ }^{1}$

\begin{tabular}{|c|c|c|c|c|}
\hline $\begin{array}{c}\text { Social } \\
\text { Group/Land } \\
\text { Irrigated }\end{array}$ & $\mathbf{0 - 0 . 1}$ ha & $\mathbf{0 . 1 - 2 . 5}$ ha & $\mathbf{> 2 . 5}$ ha & Total \\
\hline ST & 80.55 & 18.48 & 0.97 & 100 \\
& $(12.93)$ & $(6.86)$ & $(4.05)$ & $(10.91)$ \\
\hline SC & 77.42 & 2.14 & 0.44 & 100 \\
& $(24.39)$ & $(16.12)$ & $(3.64)$ & $(21.42)$ \\
\hline Others & 62.96 & 33.48 & 3.56 & 100 \\
& $(62.67)$ & $(77.02)$ & $(92.31)$ & $(67.67)$ \\
\hline Total & 67.98 & 29.41 & 2.61 & 100 \\
& $(100)$ & $(100)$ & $(100)$ & $(100)$ \\
\hline
\end{tabular}

1. Land irrigated during July 2003 and June 2004.

About 69 per cent of individuals belonged to ST households without an adult with primary education (in other words, these households comprised adults who were either illiterate or literate). About 11 per cent of the ST individuals belonged to households in which an adult had primary education. Barely 8 per cent of the ST belonged to households that included an adult with >Middle level of education. Among the SC, a slightly lower proportion of the individuals (about 65 per cent) belonged to households that lacked an adult with primary education. A slightly higher proportion of individuals (about 12 per cent) belonged to households that included an adult with primary 
education. About 11 percent of the ST individuals belonged to households that had an adult with >Middle education. Thus between the ST and SC, the latter were slightly better endowed in terms of human capital. The disparity between these two groups and Others was marked. The proportion of individuals who belonged to the latter without an adult with primary education was the lowest but high (about 51 per cent) while that of individuals in households with an adult with >Middle education was twice as high as among the SC.

Table 4

Cross-Classification of SC, ST, and Others by Highest Educational Level (Adult) ${ }^{1}$

\begin{tabular}{|c|c|c|c|c|}
\hline $\begin{array}{c}\text { Educational } \\
\text { Level/Social } \\
\text { Group }\end{array}$ & ST & SC & Others & Total \\
\hline Illiterate & 13.43 & 24.64 & 61.93 & 100 \\
& $(61.94)$ & $(57.85)$ & $(42.58)$ & $(47.68)$ \\
\hline Literate & 11.44 & 19.13 & 69.43 & 100 \\
& $(8.92)$ & $(7.60)$ & $(8.07)$ & $(8.07)$ \\
\hline Primary & 8.38 & 17.87 & 73.75 & 100 \\
& $(10.68)$ & $(11.60)$ & $(14.02)$ & $(13.18)$ \\
\hline Middle & 7.38 & 16.66 & 75.96 & 100 \\
& $(10.66)$ & $(12.25)$ & $(16.35)$ & $(14.93)$ \\
\hline$>$ Middle & 4.99 & 13.46 & 81.55 & 100 \\
& $(7.79)$ & $(10.70)$ & $(18.97)$ & $(16.14)$ \\
\hline Total & 10.34 & 20.31 & 69.36 & 100 \\
& $(100)$ & $(100)$ & $(100)$ & $(100)$ \\
\hline
\end{tabular}

1. An adult household member is $>18$ years. As this and the two following tables are based on individual files, the relative frequencies refer to proportions of individuals.

The disparities are indeed glaring in Table 5 where the ST, SC and Others are crossclassified by highest educational attainments of an adult female household member.

Table 5

Cross-Classification of SC, ST, and Others by Highest Educational Level (Female) ${ }^{1}$

\begin{tabular}{|c|c|c|c|c|}
\hline $\begin{array}{c}\text { Educational } \\
\text { Level/Social } \\
\text { Group }\end{array}$ & ST & SC & Others & Total \\
\hline Illiterate & 12.50 & 23.78 & 63.72 & 100 \\
& $(75.07)$ & $(72.80)$ & $(56.76)$ & $(61.89)$ \\
\hline Literate & 9.81 & 17.38 & 72.80 & 100 \\
& $(6.27)$ & $(5.66)$ & $(6.89)$ & $(6.58)$ \\
\hline Primary & 6.86 & 15.86 & 77.29 & 100 \\
& $(7.40)$ & $(8.72)$ & $(12.37)$ & $(11.12)$ \\
\hline Middle & 6.64 & 14.12 & 79.24 & 100 \\
& $(6.86)$ & $(7.43)$ & $(12.13)$ & $(10.64)$ \\
\hline$>$ Middle & 4.64 & 11.14 & 84.22 & 100 \\
& $(4.40)$ & $(5.39)$ & $(11.85)$ & $(9.78)$ \\
\hline Total & 10.30 & 20.21 & 69.48 & 100 \\
& $(100)$ & $(100)$ & $(100)$ & $(100)$ \\
\hline
\end{tabular}

1. Highest educational level of an adult female member. 
About 81 per cent of the ST individuals belonged to households without an adult female with primary education, while the corresponding percentages for the SC and Others were 78 per cent, and 63 per cent, respectively. A similar pattern is observed for these three groups when they are cross-classified by primary education and higher levels. The proportion of individuals in Others with an adult female who possessed >Middle education nearly three times that of the ST and twice that of the SC. But, above all, what is striking is the relatively low proportions of individuals belonging to ST and SC households with adult females possessing primary or higher levels of education.

\section{Table 6}

Cross-Classification of SC, ST, and Others by Occupation ${ }^{1}$

\begin{tabular}{|c|c|c|c|c|}
\hline $\begin{array}{c}\text { Occupation/Social } \\
\text { Group }\end{array}$ & ST & SC & Others & Total \\
\hline Self-emp non-agr & 4.66 & 19.43 & 75.92 & 100 \\
& $(6.67)$ & $(14.16)$ & $(17.52)$ & $(15.61)$ \\
\hline Agr Labour & 14.22 & 34.05 & 51.73 & 100 \\
& $(34.88)$ & $(42.53)$ & $(20.46)$ & $(26.76)$ \\
\hline Other Labour & 11.08 & 30.34 & 58.58 & 100 \\
& $(10.88)$ & $(15.17)$ & $(9.28)$ & $(10.71)$ \\
\hline Self-emp-agr & 11.79 & 11.55 & 76.65 & 100 \\
\hline Others & $(38.43)$ & $(19.17)$ & $(40.27)$ & $(35.55)$ \\
\hline Total & 8.78 & 16.90 & 74.32 & 100 \\
& $(9.15)$ & $(8.97)$ & $(12.48)$ & $(11.37)$ \\
\hline & 10.91 & 21.42 & 67.67 & 100 \\
& 100 & 100 & 100 & 100 \\
\hline
\end{tabular}

1. Occupational classification is based on largest source of household income.

Let us first consider the distributions of the ST, SC and Others among the self-employed in agriculture and non-agriculture. A vast majority of the self-employed in agriculture (about 76 per cent) were Others, and relatively small but nearly equal proportions belonged to the ST and SC households (about 12 per cent). Among the self-employed in non-agriculture, again Others were a large majority (about 76 per cent), followed by the SC (about 19 per cent), and then the ST (about 5 per cent). The shares of ST and SC households were higher among agricultural and non-agricultural labour- those of the latter were more than twice as high. Given the much larger number of Others, it is not surprising that they comprised the majority in both occupations. No comment is offered on the shares in the residual occupational group, Others.

Let us now turn to the occupational distribution within each social group. The highest proportion of the ST households were self-employed in agriculture (over 38 per cent), followed by agricultural labour (about 35 per cent). Self-employed in non-agriculture and other labour accounted for relatively small shares. The SC, by contrast, had the highest share in agricultural labour (over 42 per cent), followed by self-employed in agriculture (about 19 per cent), and then self-employed in non-agriculture (about 14 per cent). Others were highly concentrated in self-employed in agriculture (over 40 per cent), followed by agricultural labour (over 20 per cent), and then self-employed in nonagriculture (about 18 per cent).

(b) Incidence and Intensity of poverty 
The overall incidence of poverty in rural India in 2004-05 was high, as about a quarter of the households were poor. There was, however, substantial variation across the social groups. Among the ST, about 44 per cent of the households were poor, as against 32 per cent among the SC and about 19 per cent among Others.

Table 7

Cross-Classification of SC, ST and Others by Poverty Status ${ }^{1}$

\begin{tabular}{|c|c|c|c|c|}
\hline $\begin{array}{c}\text { Poverty } \\
\text { Status/Social } \\
\text { Group }\end{array}$ & ST & SC & Others & Total \\
\hline Poor & 19.22 & 27.74 & 53.03 & 100 \\
& $(43.79)$ & $(32.19)$ & $(19.48)$ & $(24.85)$ \\
\hline Non-Poor & 8.16 & 19.33 & 72.51 & 100 \\
& $(56.21)$ & $(67.81)$ & $(80.52)$ & $(75.15)$ \\
\hline Total & 10.91 & 21.42 & 67.67 & 100 \\
& $(100)$ & $(100)$ & $(100)$ & $(100)$ \\
\hline
\end{tabular}

1. The poverty cut-off point is Rs 358 per capita per month.

Table 8

Cross-Classification of SC, ST and Others by Expenditure and Intensity of Poverty

\begin{tabular}{|c|c|c|c|c|}
\hline $\begin{array}{c}\text { Poverty } \\
\text { Status/Social } \\
\text { Group }\end{array}$ & ST & SC & Others & Total \\
\hline Poor & 265 & 284 & 293 & 285 \\
$(25.98)$ & 595 & 615 & 748 & $(20.39)$ \\
\hline Non-Poor & 451 & 508 & 659 & 710 \\
\hline Total & (20.67) & 604 \\
\hline
\end{tabular}

1. Figures without parenthesis are monthly per capita expenditure. Figures within parenthesis are expenditure-poverty gaps. This gap is defined for the poor as the (difference between poverty cut-off point and per capita monthly expenditure of a poor household/poverty cut-off point) x 100 .

Not only was the incidence of poverty highest among the ST, but also the intensity of poverty. The SC had a lower intensity of poverty than Others but the gap was nonnegligible.

As shown below in Fig: 1, the cumulative per capita expenditure distribution curve lies below that for the SC, and the latter below that for the ST over the range of poverty thresholds considered ( 25 per cent and 50 per cent higher than the threshold of Rs 358 ). It follows therefore that, over the range of poverty thresholds, (i) poverty is lowest in the Foster-Greer-Thorbecke (FGT) class of poverty indices among Others; and (ii) lower among the SC relative to the ST. So regardless of the poverty cut-off point and the poverty index used, the ST were the poorest ${ }^{10}$.

\footnotetext{
${ }^{10}$ The head-count ratio, income-poverty gap and a distributionally sensitive poverty index that assigns higher weights to income gains of the poorest are special cases of the FGT class of poverty indices. For an exposition, see Ravallion (1992) and Gaiha (1993).
} 
Figure 1: Monthly per capita expenditure in Rural India

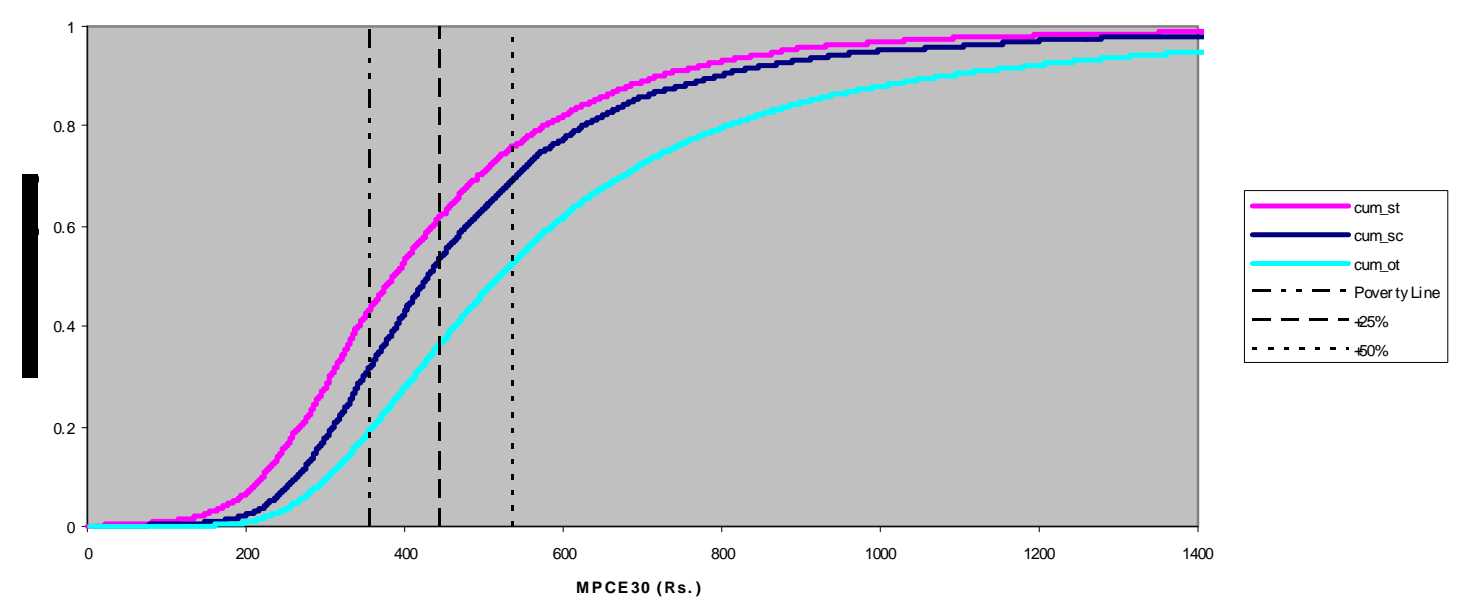

\section{(c) Decomposition of Poverty}

Here a decomposition of average or expected probability of poverty by social group is carried out. As noted earlier, this has two components: one is the characteristic component and the other is the structural component. Pair-wise comparisons of the ST and SC are carried out with Others as the reference group ${ }^{11}$.

The results of the decomposition are summarised below.

The contrast between the ST and SC in terms of characteristic and structural components is striking. Between the ST and Others, structural differences account for about 59 per cent of the difference in the probabilities of being poor while between the SC and Others the larger component is that associated with differences in characteristics (about 55 per cent). A disaggregation of these components reveals that: (i) between the ST and Others, the highest contributor to the characteristic component is location, followed by education and then occupation; (ii) a very large share of the structural component is attributable to location, with returns to occupation, demographic characteristics and education accounting for relatively small shares. Between the SC and Others, on the other hand, occupation accounted for the largest share of the characteristic component, followed by education and then land. There are, however, sharp changes in the disaggregated structural components. The largest component is location, followed by occupation and education ${ }^{12}$. So, although the SC are more dispersed than the ST, they are also subject to lower returns.

Some results are different with the reference group being the aggregate sample of households. First, as expected, the poverty gaps are smaller both for the ST and SC. Second, the structural component is slightly lower than the characteristic component for the ST but still large. Within the latter, education and region are relatively large, while in the former, the regional contribution dominates. Among the SC, the characteristic

11 For computational details, see Gaiha et al. (2007).

12 Recall that these results are similar to those reported by Gang et al. (2006). 
component is slightly larger, as in the previous decomposition. Occupation, education and land account for a relatively large share, as before. In the structural component, location dominates but not as much as among the ST. So these results are largely similar to those reported earlier with a different decomposition.

In sum, the poverty among the ST and SC is higher both because of differences in characteristics and returns on them. However, their relative importance varies. It is a matter of policy concern that much of the deprivation of the ST is linked to lower returnsespecially their location in remote, inaccessible areas with weak infrastructure support.

\section{(d) Decomposition of Inequality}

In order to assess the sources of disparity in living standards of, say, the ST and Others, we first estimate expenditure functions for each group separately ${ }^{13}$. In the next step, using a procedure similar to the decomposition of poverty, we decompose the difference in per capita expenditure into characteristic and structural components.

Between the ST and Others, the differences in characteristics account for a little over 50 per cent of the disparity in expenditure, implying a nearly equal contribution of structural differences. Between the SC and Others, however, the relative contributions differ considerably with the characteristic component accounting for 60 per cent of the disparity in expenditures.

Disaggregation of the characteristic component between the ST and Others reveals that the largest contributor is location, followed by education and then occupation. The structural component, on the other hand, is largely made up of differences in returns to location, followed by differences in returns to demographic characteristics, and landowned.

Between the SC and Others, occupation was the largest contributor to the characteristic component, followed by education and then land. The structural component, on the other hand, is attributable largely to differences in returns to location and educational attainment, offset partly by the higher occupational returns.

In sum, as in the case of poverty decomposition, the relative contributions of characteristics and structural components of disparity in living standards vary between the ST and Others, and between the SC and Others. In general, within each component, location, occupation and education mattered a great deal, while their relative importance varied with the social group ${ }^{14}$.

\section{Discrimination, identity and deprivation}

Although conclusive evidence on discrimination is not found, it cannot be ruled out in view of large differences in characteristics (e.g. human capital, physical capital, occupations) and returns to them between the two disadvantaged groups-especially the ST. A brief review of alternative conceptualizations of discrimination and some recent experimental evidence offers insights into the forms it takes and measurement problems.

${ }^{13}$ For details of the estimation of expenditure function, see Gaiha et al. (2007).

${ }^{14}$ These results are not dissimilar to those reported in Kijima (2006). 
Let us first make a distinction between current and historical forms of discrimination. Referring to our decomposition of poverty incidence gaps, the differences in endowments could be a result of oppression of some disadvantaged groups (e.g. social exclusion of the SC and ST restricted their access to education over a long period and that in turn restricted their children's access to it). The differences in returns to various endowments, on the other hand, may reflect discretionary valuation of performance and thus elements of current discrimination. While this is a useful classification, it is somewhat problematic in so far as current performance may also be shaped by personal identity and motivation in complex ways. In particular, social exclusion and discriminatory reward systems may undermine self-confidence and motivation to excel, and consequently performance.

In an important measure of discrimination-referred to as statistical discrimination- under some circumstances, employers use the average quality of a given race/caste/ethnic group to predict the quality of individuals of that group (Arrow, 1972). A difficulty, however, is that in such a model there is no incentive for self-improvement, since all members of the group in question are judged the same and therefore paid the same wage irrespective of individual merit. Thus prejudice produces lower level equilibrium trap.

A strikingly different formulation is due to Becker (1971) in which discrimination is explained by tastes. Any individual with positive taste for discrimination receives positive economic rewards for reducing this taste. Hence discrimination persists despite economic incentives. In contrast, in Arrow's model, discrimination exists at least partially because of economic incentives.

Akerlof (1976) proposed an insightful model of caste equilibrium in which caste customs are obeyed, yet no single individual, by behaving differently, can make himself better-off. As long as most persons have positive utility for adhering to social customs and as long as activities are pursued up to the point where marginal benefits equal marginal costs, there will be rewards to breaking social customs if they fail to promote economic efficiency. However, without ruling out deviant behaviour, Akerlof (1976) conjectures that usually the returns are greater to those who do not break social customs. As he states, "In a segregationist society, such persons discriminate; in a caste society, they follow the caste code". As a result, social customs endure and the caste equilibrium is maintained.

In a more recent and richer formulation, Akerlof and Kranton (2000) focus on identityrelated behaviour and how it influences economic outcomes. The building blocks are: (i) people have identity-based payoffs derived from their own actions; (ii) people have identity-based payoffs derived from others' actions; (iii) third parties can generate changes in these payoffs; and (iv) some but not all individuals can choose their identity. In a poor and socially excluded community, some will identify with the dominant culture, while others reject it and the subordinate position assigned to those of "their race, class or ethnicity" (Akerlof and Kranton, 2000, p. 85). The former engage in remunerative activities (in line with the dominant culture) and the latter "engage in self-destructive behaviour" manifesting in "Taking drugs, joining a gang....." (p.85). This is not just typical of persistent pockets of poverty (e.g. black ghetto poverty) but also offers a less monolithic view of poverty than current economic theories that emphasise conformity. 
In general, the greater the social exclusion, the greater the possibility of equilibria in which individuals forego remunerative activities. How caste salience and mistrust affect performance of those at the lowest rung of social hierarchy is elaborated below.

\section{Beliefs, identity and opportunity}

Recent work has drawn pointed attention to the role of culture in perpetuating inequality and deprivation. Specifically, even after coercive structures underlying subordination of one group by another are dismantled, the cultural beliefs remain intact and inequality persists. To illustrate, deep economic divides persist between blacks and whites in the United States, between untouchable castes and other castes in India, and between indigenous and non-indigenous groups in Asian and Latin American countries. As noted earlier, there are several links between belief systems and persistent inequality - one is statistical discrimination: under some conditions, employers' prior beliefs in group differences (where none exist) are self-fulfilling. Another is stereotype threat or social identity susceptibility. Specifically, when a particular social identity is made salient, performance is altered in the direction predicted by that stereotype. Two recent papers, Hoff and Pandey (2005) and Hoff et al. (2005), offer persuasive experimental evidence from Uttar Pradesh (UP) to illustrate the self-fulfilling nature of the belief system of socially inferior groups/castes. As individuals from such groups believe that their efforts will be judged in a biased way, their motivation to perform well is weak. So making social identity salient would have a larger effect on behaviour when the evaluation is discretionary, relative to a non-discretionary evaluation. No such difference would be observed for the social group that is not stigmatised.

Two sets of results are reported. In the first experiment, low-caste and high caste junior high school male students in Uttar Pradesh (UP) are asked to solve mazes under various incentive schemes. In some cases, caste is made salient through a public announcement of the children's caste. When this happens, the performance of lowcaste children is significantly worse-both relative to their own performance when their social identity is not revealed and relative to the performance of the high caste.

The second experiment focuses on the role of mistrust. A condition is devised that manipulates the scope for judgment in rewarding performance. When the subjects were asked to accept or reject a gamble in which there was no scope for judgment by the evaluator, making caste salient did not result in a caste gap. But in other cases of discretionary evaluation, making caste salient has a significant effect.

These results highlight that historical roots of deprivation - as in the case of the SC and ST in India-shape expectations that contribute to the persistence of group inequality. The legacy of past prejudices and deprivation perpetuate subordination of some groups. A low caste individual is more likely to submit to the authority of the high caste if he believes that others will do so, too. A high-caste person is more likely to exercise that authority if he believes that the low-caste will submit. Thus a shared system of beliefs stabilises and coordinates expectations, and contributes to reproduction of inequality over time.

\section{Quotas for women, SC, and ST in state legislatures}


The question of whether mandatory reservations in state legislatures influence policies is examined in a recent contribution (Pande, 2003).

The Indian constitution mandates political reservation in favour of Scheduled Castes and Scheduled Tribes in every state. In addition, it directs state governments to use public policy to improve the well-being of these two groups.

The reservation for a group reflects the group's population share in the state. However, revision of these quotas is carried out only after a new census estimates become available. Thus, while a group's population share varies continuously, the reservation changes with a lag. The author exploits this institutional feature to identify the effect of quotas on policy outcomes. Or, more specifically, it allows the author to disentangle the effects of changes in the political representation for a group from those due to changes in its population share.

Views on the efficacy of political representation through quotas differ ${ }^{15}$. One sceptical view is that, since SC and ST legislators have to lobby with both upper-caste constituents in reserved jurisdictions and with the primarily upper -caste membership of party committees, they have little autonomy in pursuing their policy preferences or agenda. A contrary and more optimistic view is that minority legislators act en bloc, and, as a consequence, succeed in pursuing their own agenda. Given such a divergence of views, Pande's (2003) analysis makes a valuable contribution through a rigorous econometric analysis, based on a model of political competition with limited policy commitment. Her findings supporting quotas as a redistribution tool are consonant with the view that complete political commitment is absent from democracies. So a candidate's personal "ideology" is a key determinant of observed policy outcomes.

The analysis is based on a panel data set for 16 major states over the period 1960-92. In the sample, the average SC reservation was 13 per cent, and the ST reservation was 7 per cent. In the analysis carried out, two types of policies are distinguished: general and targeted. The first refers to policies not restricted to the SCs and STs, and the second to those explicitly targeted to them. In the general category, the items included are (i) state government expenditure, (ii) education expenditure, and (iii) land reform. The second category of targeted policies includes (i) fractions of state expenditure devoted to SC and ST welfare schemes (e.g. group housing projects, provision of public goods in SC and ST hamlets), and (ii) job quotas (or, fractions of state government jobs reserved for the SCs and STs). The mean fraction of jobs so reserved was 20 per cent. The analysis yields the following results:

- Increases in ST reservation raise state public expenditure.

\footnotetext{
${ }^{15}$ An issue is whether in the absence of reservation disadvantaged groups would be underrepresented. Duflo (2004) is emphatic that this is likely to be the case on the basis of the following evidence: (i) Very few women, SCs or STs are elected without reservations. In the Gram Panchayat (village council) in the two districts in West Bengal and Rajasthan that were not reserved for women, 6.5 per cent and 1.7 per cent of Pradhans were women, respectively. In West Bengal, 7.5 per cent of the not reserved Gram Panchayat not reserved for SCs had a SC Pradhan. But it is debatable whether greater representation of disadvantaged groups translates into welfare improvement (Gaiha and Kulkatni, 2006).
} 
- ST reservation, however, has a significant negative effect on educational expenditure. This is somewhat intriguing given the low levels of literacy among the ST.

- Higher numbers of SC and ST legislators do not have any effect on land reform legislation.

There is a significant relationship between SC and ST reservations and targeted policies.

- There is a positive correlation between SC reservation and job quotas. A 1 per cent increase in SC reservation is associated with a 0.6 per cent increase in job quota. However, ST reservation does not have a significant effect on job quotas.

- ST reservation has a significant effect on ST welfare spending. The estimates suggest that a one point increase in ST reservation increases the share of ST welfare spending by 0.8 percentage point.

Is there an explanation of these differences? Pande (2003) offers the following explanation: relative to ST, SC individuals are both more educated and geographically more dispersed. Hence, their relative returns from individual-specific policies, such as job quotas, are higher. On the other hand, relative to SC, the benefits to ST from geographically localised welfare programmes such as housing are greater. It is further emphasised that increases in SC current population shares are associated with increases in job quotas and reductions in ST welfare spending. These findings are claimed to be consistent with differences in the political activism of the SC and ST. In general, it is believed that, while the SC are an important political block, the ST remain politically marginalised. However, more can be said on the basis of other evidence, as discussed below.

As argued and elaborated below, some key questions remain unresolved. Specifically, we need to examine why inequities persist between the SCs and STs, on the hand, and between the SCs and STs, and Other, on the other. Whether correction of imbalances in political agency corrects other inequities may in fact be conditional on the nature of the political regime, social mobilisation and group identity of the disadvantaged.

\section{Political regime, social mobilisation and group identity}

It is not just legislative measures which matter, but also their interaction with sociopolitical and economic forces. This is illustrated through an analysis of land distribution. Mohanty (2001) reviews (i) the legislative measures enacted for the protection and promotion of land rights of the SC and ST, and their achievements; (ii) the changes in land distribution among them; and (iii) the factors that have impeded improvements in their landownership. Briefly, his findings are as follows: (i) Inherent loopholes and ambiguities in the legislative measures, bureaucratic inefficiency, lack of updated land records, and ignorance of SC and ST beneficiaries have come in the way of land transfers. (ii) The distribution of area operated during 1980-81 and 1990-91 shows little improvement. At the all-India level, the share of the SCs in area operated rose slightlyfrom 7.03 per cent in 1980-81 to 7.90 per cent in 1990-91, while that of the STs rose from 10.20 per cent to 10.80 per cent. (iii) However, there is considerable variation among the states. Bihar's performance, for example, has been dismal. This is 
attributable to a feudal social structure, and its reflection in state politics; a legal system that is heavily tilted against the disadvantaged; and weak organisation of the SCs and STs. By contrast, Tamil Nadu did better as the dominance of upper castes was challenged. The DMK -a regional party- successfully mobilised the lower castes against the upper castes. Karnataka is yet another interesting case where the Dalit movement challenged their oppressors. In fact, it turned out to be the strongest and longest-lasting Dalit movement in the country. It follows therefore that legislative measures are of no consequence in the absence of a political regime that identifies itself with the disadvantaged groups, and the latter are well-organised to assert their legitimate demands ${ }^{16}$.

Not only do the provisions in the Constitution vary for the SC and ST, it is argued that there are specific reasons why their group identities are different (Xaxa, 2001). ${ }^{17}$ Specifically, the ST have played a second fiddle to the SC in taking advantage of the resources granted to them, whether it is education, science and technology or civil service and politics. The ST, on the other hand, were given reservations as they lived in isolation from the dominant community in remote, inaccessible areas. The SC have had greater exposure to the larger society as compared to the ST. Although the opportunities open to the larger society or the upper castes in the form of knowledge, information and technology, and employment were also in sight for the SC, they were denied access to them. By contrast, such opportunities did not exist for the ST because of their isolation from the mainstream in all its manifestations- customs, traditions and values.

Although exposure of the STs has grown over the years, an explanation for the relative disparity between the SC and ST must go beyond limited exposure of the latter. Xaxa (2001) argues that it lies in the social structure of the ST. (i) Tribal societies are typically small and marked by homogeneity ${ }^{18}$. A lack of heterogeneity in terms of social division of labour, occupation, skill, class, access to power has the consequence that there is no reference group to emulate. (ii) There is nothing like tribal identity at the pan-India level. If there is an identity of any kind, it is confined to a locality or a region. Moreover, such an identity is more at work at the political or interest articulation level than at the social or cultural plane. But, more importantly, even when this occurs, it is less assertive than among the SC. The SC have had reference points within the system (i.e. the upper caste) as also within their own category both at the regional and national levels. (iii) Collectivity and not individuality remains the hallmark of tribal societies. Hence the principle of individual excellence is not valued much. (iv) It is therefore not surprising that the Constitutional provisions created opportunities that benefited the SC more than the ST.

Another distinct but related issue is that both within the SC and ST some groups fared better than others ${ }^{19}$. Among the SC, for example, the Mahars of Maharashtra or

\footnotetext{
${ }^{16}$ In such states, atrocities against the SC and ST are fewer and less violent (Mohanty, 2001).

${ }^{17}$ In fact, there are more provisions for ST than for SC. The Articles 15 (4), 16 (4), 19 (5), 23, 46, 330, 332, 334, 335, 338 are common to both. Articles 29, 164, 244, 244 (A), 275 (1), 339 (1), 339 (2) pertain only to the Scheduled Tribe. Besides, there are Articles 371 (A), 371 (B) and 371 (C), which are in force only in the north-eastern region (Xaxa, 2001).

${ }^{18}$ They are small in relation to the dominant community but they vary in size. The size varies from 7 million in the case of the Gonds and Bhils to less than one thousand in some cases (Xaxa, 2001).

${ }^{19}$ On this issue, see also Radhakrishna and Ray (2005).
} 
Chamars and Jatavs of north India fared better than others. Similarly, among the ST, the Minas of Rajasthan, Mizos of Mizoram, Khasis of Meghalaya have performed better. What seems to account for the superior performance of the Minas is the differentiation among them depending on their geographical spread, nature of intermingling with caste groups (e.g. Jats, Ahirs), and occupational choice. As landlords/Zamindars they were a privileged group; interacted more frequently with state authorities; and, as a result, were in an advantageous position to benefit from mandatory reservations ${ }^{20}$.

In sum, these are some of the structural elements that help understand better the disparity between the SC and ST, as also within each category.

\section{Concluding observations}

Our analysis of the $61^{\text {st }}$ round of the NSS confirms higher incidence and intensity of poverty among the STs and SCs, relative to non-ST/SC. A decomposition of poverty gap between these two groups and Others corroborates earlier findings. Two components the characteristics and structural- are quantified. The first focuses on differences in household characteristics-including demographic, ownership of land, educational attainments, location, and occupations-and the second on differences in returns to these characteristics. A large part of the poverty gap between the STs and Others is due to differences in returns or structural differences while among the SCs it is due largely to differences in characteristics.

Whether these structural differences are a reflection of discrimination is far from selfevident. There are several issues. One is the meaning of discrimination itself. Generally, it is taken to mean that equal persons are treated unequally (the decomposition results, for example differ somewhat when the reference group is a composite category of the STs, SCs and Others). A second issue is: should discrimination be limited to differences in returns to assets, or should it be broadened to include historical factors associated with differential access to endowments? There is abundant evidence corroborating that the SCs and STs, compared to upper caste Hindus, are more likely to be ill, less likely to be educated, more likely to cultivate land, and to live in a climate of fear and oppression. If anything, the interpretational problems are compounded in the broader interpretation but that alone cannot be a reason for preferring a limited and potentially misleading interpretation.

\footnotetext{
${ }^{20}$ In a recent contribution, Bertrand et al. (2005) argue emphatically that psychological evidence points to implicit discrimination, as opposed to explicit discrimination in the two approaches delineated here. This rests on the presumption that conscious processing activates different regions in the brain than does unconscious processing. In fact, it is argued that even theoretically controllable behaviour operates with greater automaticity under certain conditions-time pressure or other cognitive load, and ambiguity. An example cited is African-American cab drivers receive lower tips than white cab drivers. In that case, it is not obvious what is to be made of explicitly stated beliefs or judgments. A further complication arises when personal identity is multidimensional, as articulated by Sen (2006). As he emphasises, "In our normal lives, we see ourselves as members of a variety of groups-we belong to all of them. A person's citizenship, residence, geographic origin, gender, class, politics, profession, employment, food habits, social commitments etc. make us members of a variety of groups. Each of these collectivities, to all of which this person simultaneously belongs, gives her a particular identity. None of them can be taken to be the person's only identity or singular membership category" (p.5). This of course does not rule out some dimensions assuming greater importance under specific situations.
} 
Even with regard to measurement of 'current' discrimination, there are at least two approaches. One is the statistical approach in which the average performance of a group determines remuneration. So (average) wage disparity may be justified in terms of economic incentives. An alternative approach focuses on taste for discrimination where wage disparity occurs despite economic incentives. Empirically, however, it is difficult to disentangle these effects (wage rates for women under the Employment Guarantee Scheme, for example, are generally lower). The policy design therefore cannot be limited to enhancing the endowments of the STs, SCs and other disadvantaged groups-women from these groups, for example, have to bear the double burden of deprivation-but must also address the issue of lower returns ${ }^{21}$. While some of the disparity may have elements of discrimination, subject of course to the measurement problems, it is arguable that lower quality of education, location in remote, inaccessible areas with limited infrastructure and market access cause poverty and inequity to persist.

While quotas at different levels (e.g. state legislatures) are associated with favourable effects on disadvantaged groups, acute poverty and disparities in living standards persist. An issue that our analysis highlights is that identity could have a potentially important role too in perpetuating deprivation. Salience of caste and tribal affiliations together with mistrust of the reward system (or belief system) -confirmed by recent experimental evidence-have to be dealt with in designing affirmative action.

What is important from a policy perspective is that the social categories and behavioural prescriptions can be influenced (through, for example, expansion of education and employment opportunities). More specifically, as Akerlof and Kranton (2000) emphasise, providing employment and training facilities outside a poor neighbourhood would avoid the negative interactions with the non-conformists (or those with 'oppositional' identities). In the context of expansion of schooling, it is imperative that those from socially excluded groups are protected against a sense of alienation or loss of identity in pursuing an activity that conforms to the dominant culture. Moreover, the rhetoric and symbolism of the affirmative action debate matters as it influences the level of social exclusion. One view is that portraying the ST and SC as victims in affirmative action programmes may prove costly to these groups and exacerbate their oppositional identities or non-conformist behaviour. But if the same action or programme is projected as an "apology for previous discrimination and an invitation for...admission to the dominant culture" (p. 90) it could reduce the level of social exclusion. In micro-finance, for example, mixed self-help groups may allow greater interaction between social groups than segregated groups. One of the reasons cited for the Employment Guarantee Schemes's spectacular role in mobilisation of the rural poor was that working together helped in overcoming caste, religious and ethnic barriers. Alongside, strengthening of rural infrastructure and easier market access would facilitate mobility, intermixing of different groups, and expand opportunities for more productive employment.

\section{Annex}

${ }^{21}$ On the question of double burden of women from disadvantaged groups, see Deshpande (2007). 
Table A.1

Legal Identification of Scheduled Castes and Scheduled Tribes

\begin{tabular}{|c|}
\hline Selection Criteria for Scheduled Castes \\
\hline 1.Cannot be served by clean Brahmins \\
\hline $\begin{array}{l}\text { 2. Cannot be served by the barbers, water carriers, tailors, etc. who serve the caste } \\
\text { Hindus }\end{array}$ \\
\hline 3. Pollutes a high caste Hindu by contact or by proximity \\
\hline 4. Is one from whose hands a caste Hindu cannot take water \\
\hline 5. Is debarred from using public amenities such as roads, ferries, wells, or schools \\
\hline $\begin{array}{l}\text { 6. Will not be treated as an equal by high-caste men of the same educational } \\
\text { qualification }\end{array}$ \\
\hline $\begin{array}{l}\text { 7. Is depressed on account of the occupation followed and, but for that, occupation } \\
\text { would subject to no social disability }\end{array}$ \\
\hline Selection Criteria for Scheduled Tribes \\
\hline 1. Tribal origin \\
\hline 2. Primitive ways of life and habitation in remote and less accessible areas \\
\hline 3. General backwardness in all respects \\
\hline
\end{tabular}

Source: Pande (2003) 


\section{References}

Akerlof, G. (1976) "The Economics of Caste and of the Rat Race and Other Woeful Tales", Quarterly Journal of Economics, vol. 90.

Akerlof, G. and R. E. Kranton (2000) "Economics and Identity", Quarterly Journal of Economics, vol. 115 (3).

Arrow, K. (1972) "Models of Job Discrimination", and "Some Mathematical Models of Race Discrimination in the Labour Market", in A. H. Pascal (ed.) Racial Discrimination in Economic Life, Lexington MA: D. C. Heath.

Becker, G. (1971) The Economics of Discrimination, Chicago: University of Chicago Press.

Bertrand, M., D. Chugh, and S. Mullainathan (2005) "Implicit Discrimination", American Economic Review, vol.95, no. 2.

Borooah, V. (2005) "Caste, Inequality and Poverty in India", Review of Development Economics, vol. 9, no. 3.

Borooah, V., A. Dubey and S. Iyer (2007) "The Effectiveness of Job Reservations: Caste, Religion and Economic Status in India", Development and Change, vol. 38.

Deshpande, A. (2007) "Overlapping Identities under Liberalisation: Gender and Caste in India”, Economic Development and Cultural Change, vol. 55 (4).

Duflo, E. (2004) "Why Political Reservations?" Department of Economics, MIT, (mimeo).

Gaiha, R. (1993) Design of Poverty Alleviation Strategy in Rural Areas, FAO Economic and Social Development Paper 115, Rome: FAO.

Gaiha, R., and Vani S. Kulkarni (2006) "Common Interest Groups, Village Institutions and the Rural Poor: A Review of the District Poverty Initiatives Project", Contemporary South Asia, vol. 15 (1).

Gaiha, R., G. Thapa, K. Imai and Vani S. Kulkarni (2007) "Endowments, Discrimination and Deprivation among Ethnic Groups in Rural India", Rome: IFAD (draft).

Gang, I., K. Sen and M-Su Yun (2006) "Poverty in Rural India and Caste", New Brunswick NJ: Rutgers University, mimeo.

Hoff, K. and P. Pandey (2005) "Opportunity is not Everything: How Belief Systems and Mistrust Shape Responses to Economic Incentives", Economics of Transition, vol. 13 (3).

Hoff, K,. P. Pandey and M. Dasgupta (2005) "Institutional Inertia in Local Government: Evidence from an Indian Village with Mandated Political Reservations", Washington DC: World Bank, (mimeo). 
Kijima, Y. (2006) "Caste and Tribe Inequality: Evidence from India, 1983-1999", Economic Development and Cultural Change, vol 54

Kozel, V. and B. Parker (2003) "A Profile and Diagnostic of Poverty in Uttar Pradesh", Economic and Political Weekly, January, 25.

Lanjouw, P. and N. Stern (1991) "Poverty in Palanpur", World Bank Economic Review, vol. 5 (1).

Mohanty, B. B. (2001) "Land Distribution among Scheduled Castes and Tribes", Economic and Political Weekly, October 6.

Neumark, D. (1988) "Employers' Discriminatory Behaviour and the Estimation of Wage Discrimination", Journal of Human Resources, vol. 23 (3).

Pande, R. (2003) "Can Mandated Political Representation Increase Policy Influence for Disadvantaged Minorities? Theory and Evidence from India", American Economic Review, vol. 93 (4).

Radhakrishna, R., and S. Ray (ed.) (2005) Oxford Handbook of Poverty in India: Perspectives, Policies and Programmes, New Delhi: Oxford University Press.

Ravallion, M. (1992) Poverty Comparisons, Washington DC, World Bank, mimeo.

Sen, Amartya (2006) Identity and Violence: The Illusion of Destiny, London: Allen Lane.

Xaxa, V. (2001) "Protective Discrimination: Why Scheduled Tribes Lag Behind Scheduled Castes?' Economic and Political Weekly, July 21. 


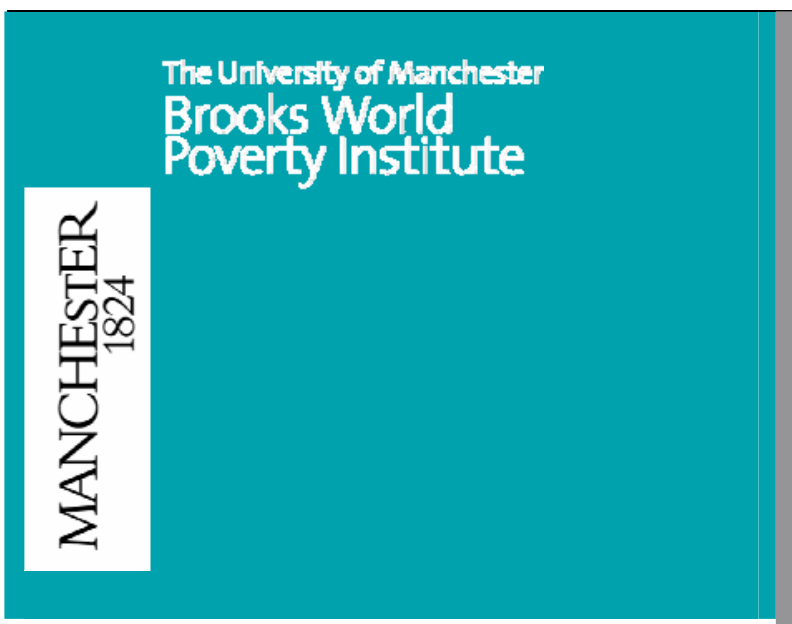

Executive Director

Professor Tony Addison

Research Director

Professor Michael Woolcock

Associate Director

Professor David Hulme

\section{Contact:}

Brooks World Poverty Institute

The University of Manchester

Humanities Bridgeford Street

Building

Oxford Road

Manchester

M13 9PL

United Kingdom

Email: bwpi@manchester.ac.uk
The Brooks World Poverty Institute (BWPI) creates and shares knowledge to help end global poverty.

BWPI is multidisciplinary, researching poverty in both the rich and poor worlds.

Our aim is to better understand why people are poor, what keeps them trapped in poverty and how they can be helped - drawing upon the very best international practice in research and policy making.

The Brooks World Poverty Institute is chaired by Nobel Laureate, Professor Joseph E. Stiglitz. 